\title{
CRENÇAS E ATITUDES LINGUÍSTICAS NA VARIAÇÃO DA VOGAL MÉDIA POSTERIOR /O/ > [U] EM POSIÇÃO TÔNICA NO PORTUGUÊS FALADO EM CAMETÁ-PA
}

\author{
LINGUISTIC BELIEFS AND ATTITUDES IN THE POSTERIOR \\ MIDDLE VOWEL VARIATION / O / $>$ [U] IN TONIC \\ POSITION IN PORTUGUESE SPOKEN IN CAMETÁ-PA
}

$\begin{array}{r}\text { Andreza Prazeres Gaia } \\ \text { http://lattes.cnpq.br/ } 19198210545365640 \\ \hline\end{array}$

Mariane Daysa de Castro Gomes ${ }^{2}$
http://lattes.cnpq.br/9767106584721131
$\underline{\text { https://orcid.org/0000-0001-6646-1510 }}$

Raquel Maria da Silva Costa Furtado ${ }^{3}$

http://lattes.cnpq.br/6834320910469690

https://orcid.org/0000-0001-6351-6192

Enviado em: 15/06/2020

Aceito em: 20/09/2020

\begin{abstract}
RESUMO: estudos sociolinguísticos de caráter quanti-qualitativo têm evidenciado forte tendência de apagamento do alteamento da vogal média posterior /o/, marca de identidade dos cametaenses, em posição tônica (COSTA 2004; RODRIGUES 2005; GAIA, GOMES e FURTADO, 2019); e o fator escolaridade é apontado em tais estudos como condicionante da manutenção de /o/ tônico, o que aparentemente indica existência de estigma associado ao uso de [buka], [kuku], [vuvu]. Portanto, a fim de verificar se o comportamento linguístico dos cametaenses de manutenção da tônica é decorrente do estigma que recai sobre o alteamento de $/ \mathrm{o} />[\mathrm{u}]$ tônico, consequentemente das crenças e atitudes acerca desse fenômeno objetivouse realizar um estudo para analisar por meio de testes de atitudes e avaliação, se o fenômeno de alteamento da vogal posterior em posição tônica é rotulado de forma positiva ou negativa na comunidade cametaense, e se essa rotulação encontra-se no nível da consciência de seus falantes. Para isso, tomou como base de análise teórica, os pressupostos teórico-metodológicos da Teoria da Variação Linguística/ Sociolinguística Quantitativa, e os estudos sobre crenças e atitudes linguisticas, advindos principalmente da Psicologia Social baseada em Lambert e Lambert (1996). O corpus para análise foi oriundo de 24 (vinte e quatro) sujeitos participantes na faixa etária de 15 a 29 anos e 30 a 45 anos, estratificados por sexo/gênero (masculino 12 e feminino 12); nível de escolaridade (08 com nível fundamental, 08 com nível médio e 08 com nível superior) e procedências (12 cametaenses 12 não cametaenses). Os resultados obtidos por meio da amostra esboçam
\end{abstract}

\footnotetext{
${ }^{1}$ Graduanda em Letras - Língua Portuguesa (Campus Universitário do Tocantins-Cametá/UFPA). Bolsista PIBIC-INTERIOR do projeto de pesquisa intitulado "Variação Linguística, Identidade, Crenças e atitudes: o falar cametaense, sob orientação da Professora Dra. Raquel Maria da Silva Costa Furtado. E-mail: andrezza.gaia333@gmail.com

2 Graduanda em Letras - Língua Portuguesa (Campus Universitário do Tocantins-Cametá/UFPA). Bolsista PIVIC do projeto de pesquisa intitulado "Variação Linguística, Identidade, Crenças e atitudes: o falar cametaense, sob orientação da Professora Dra. Raquel Maria da Silva Costa Furtado. E-mail: mariane.daysa@gmail.com

${ }^{3}$ Doutora em Linguística (UFC) em 'Descrição e Análise Linguística'. Professora Adjunta II da Faculdade de Linguagem da Universidade Federal do Pará/Campus Universitário do Tocantins/Cametá-Pará. E-mail: raqmaria@ufpa.br
} 
atitudes negativas dos informantes diante do fenômeno investigado, freando dessa forma o uso da vogal média posterior de forma alteada na posição tônica. Portanto, por meio dos resultados constatou-se à identidade e o preconceito linguístico do falante diante da língua falada de sua região.

Palavras-chave: Vogal média posterior. Crenças e atitudes linguísticas. Variação linguística. Identidade linguística.

ABSTRACT: sociolinguistic studies of a quanti-qualitative character have shown a strong tendency to erase the elevation of the posterior middle vowel / o /, the identity mark of the cametaenses, in a tonic position (COSTA 2004; RODRIGUES 2005; GAIA, GOMES and FURTADO, 2019); and the schooling factor is pointed out in such studies as a condition for the maintenance of / o / tonic, which apparently indicates the existence of stigma associated with the use of [buka], [kuku], [vuvu]. Therefore, in order to verify if the linguistic behavior of the people from the maintenance of the tonic is due to the stigma that falls on the elevation of $/ \mathrm{o} / \mathrm{P}[\mathrm{u}]$ tonic, consequently of the beliefs and attitudes about this phenomenon, the objective was to carry out a study for to analyze by means of attitudes tests and evaluation, if the phenomenon of raising the posterior vowel in a tonic position is positively or negatively labeled in the community of Cametas, and if this labeling is at the level of the consciousness of its speakers. For that, it took as a basis of theoretical analysis, the theoretical-methodological assumptions of the Theory of Quantitative Linguistic / Sociolinguistic Variation, and the studies on linguistic beliefs and attitudes, arising mainly from Social Psychology based on Lambert and Lambert (1996). The corpus for analysis came from 24 (twentyfour) subjects participating in the age group of 15 to 29 years old and 30 to 45 years old, stratified by sex / gender (male 12 and female 12); education level (08 with elementary level, 08 with secondary level and 08 with higher level) and origins (12 Cameta people 12 non Cameta people). The results obtained through the sample outline negative attitudes of the informants in the face of the phenomenon investigated, thus stopping the use of the posterior middle vowel in a high way in the tonic position. Therefore, through the results, it was verified the identity and linguistic prejudice of the speaker in relation to the language spoken in his region.

Key-Words: Posterior middle vowel. Linguistic beliefs and attitudes. Linguistic variation. Linguistic identity.

\section{Introdução}

A mensuração da valoração que o falante atribui a uma determinada variante, dialeto, ou língua, sua/seu ou de outro, de forma positiva manifesta identidade linguística sobre a variedade linguística que usa e da comunidade de fala a que pertence, porém quando essa avaliação é de forma negativa gera preconceito linguístico e estigma.

Por isso, esta pesquisa apresenta e discute por meio de métodos de dois questionários a medição de atitudes, considerando fatores sociodemográficos, com relação ao fenômeno de alteamento vocálico da média posterior em posição tônica /o/ > [u] na fala cametaense, a fim de examinar se é rotulado de forma positiva ou negativa pelos próprios falantes de Cametá e pelos não cametaenses; e se há correlação entre o uso dessas formas linguísticas e os valores sociais (noções de prestígio e desprestígio) e se essa rotulação encontra-se no nível da (in) consciência ou configura apenas como indicadores, mas não sujeitos à variação estilística, sem força avaliativa, com julgamentos sociais inconscientes. (COELHO, 2012).

Destaca-se que Cametá é um dos municípios mais antigos do estado do Pará; localiza-se à margem esquerda do Rio Tocantins e pertence à Mesorregião do Nordeste Paraense e à Microrregião de Cametá. A forte influência linguística portuguesa persiste na linguagem cametaense até nos dias atuais, haja vista que não houve a presença, no município, de processo imigratório de outras regiões brasileiras e, até mesmo, de outros países, ao longo dos trezentos e oitenta e cinco anos (385) anos de fundação da cidade, o que contribuiu para a manutenção das formas linguísticas dos

${ }^{4}$ Amostra de fala (Zona Rural, pouca escolaridade_Masculino_46 anos em diante.m4a).m4a. Extraímos deste trecho de fala exemplos de vocábulos com a vogal-alvo da pesquisa em tela, a média posterior /o/, alteada para [u] na variedade falada em Cametá. 
colonizadores portugueses, advindos de diversas regiões de Portugal, principalmente da Ilha dos Açores, segundo relatos de Silva Neto (1988) e Illari e Basso (2006), na tentativa de povoar e defender a região do Grão-Pará das invasões francesas e holandesas (COSTA, 2016).

O comportamento do sistema vocálico do Português do Brasil, em termos de língua falada, apresenta variação quando se leva em consideração a posição ocupada pelas vogais tônicas, pretônicas e postônicas, fato este observado desde Câmara Jr (1970). Assim, esta pesquisa envolve a análise de um traço linguístico identitário do falar cametaense, que é o alteamento da vogal média em posição tônica, como em /boca/ > [buca], /bolo/ > [bulu], / noite/ > [nut $[\mathrm{I}]$, pois se pretende revelar se a escolha pela manutenção e/ou alteamento de /o/ resulta de julgamento positivo ou negativo dos falantes. Entende-se que à medida que uma dada atitude negativa solidifica-se em um meio social, há predisposição à rotulação, estigmatização e segregação de falantes que utilizam variantes de menor prestígio social com base em crenças e sentimentos, e posteriormente reações estereotipadas que limitam a reverberação das peculiaridades linguísticas e identitárias.

Assim, o sentimento de estigma de falantes de grupos menores e menos prestigiados pode levá-lo ao não uso de sua forma de falar em detrimento da valoração das formas de prestígio de grupos maiores, assim como também, o sentimento de valorização e defesa da sua forma de falar e da sua comunidade podem contribuir para que seu dialeto permaneça vivo mesmo sob pressão das formas de prestígio.

O estudo orienta-se pelos pressupostos teórico-metodológicos da Sociolinguística quantitativa e em estudos sobre crenças e atitudes linguísticas (LAMBERT; LAMBERT, 1996). O corpus foi constituído por uma amostra de 24 informantes, estratificados em: faixa etária (15 a 29 e 30 a 45 anos); sexo (masculino e feminino); nível de escolaridade (pouca escolaridade, nível médio e nível superior); e procedência (cametaense e não cametaense). E para análise das atitudes dos falantes utilizouse da técnica empregada por Lambert e Lambert (1968), a de matched guise (falsos pares).

Vale resultar que o objeto da atitude não é a língua, e sim quem a usa, por isso, este estudo tem como alvo a maneira como os falantes reagem diante de sua língua e dos fatos linguísticos de outrem, e como essa atitude contribui para a criação da identidade individual e social.

Para melhor compreensão do tema desenvolvido aqui, estruturamos este artigo da seguinte maneira: Introdução; O percurso metodológico da pesquisa; Análise e discussão dos resultados sobre o fenômeno investigado; e por fim, as considerações finais e as referências.

\section{Abordagem teórica}

A língua é a base da constituição do homem, por meio dela, ele comunica-se com indivíduos de seu grupo e de outros grupos diferentes do seu; e pela natureza heterogênea que possui, apresenta-se, portanto, de diversas maneiras nos diferentes grupos sociais. E junto a isto estão as atitudes que os falantes tomam frente às variações de fala e frente a quem a realiza. Desse modo, os indivíduos manifestam atitudes movidas pelas crenças linguísticas impregnadas, ao longo do tempo pela sociedade, na língua e nos dialetos, apresentando, assim, atitudes de rejeição ou de aceitação, de preconceito ou prestígio, dentre outros.

Os estudos sobre crenças e atitudes linguísticas vêm ganhando espaço desde 1960, por meio de pesquisas em diversas áreas. Mas tiveram seu nascedouro na área da Psicologia Social com o psicólogo Allport (1954) pela obra "A natureza do preconceito" (pré-julgamento), para quem o preconceito se origina na generalização errônea e na hostilidade, apresentando duas dimensões essenciais para isso: a atitude e a crença. Para o autor as condições originárias do prejulgamento são capacidades naturais e comuns da mente humana.

Posterior aos estudos de Allport (1954), já na década de 1970, dois psicólogos e irmãos canadenses Lambert e Lambert (1975) buscaram verificar as crenças e atitudes dos falantes canaden- 
ses em relação ao francês (Língua Materna) e o inglês (Língua Oficial). Embora os estudos iniciais a respeito das crenças e atitudes linguísticas pertençam à área de Psicologia Social, atualmente outras áreas contribuem para as investigações, como por exemplo, o campo da Sociolinguística. A possibilidade de análise não somente da variação, como também da compreensão de como o falante se comporta em relação ao dialeto que fala é um dos pontos de relevância dos estudos sociolinguísticos (CARDOSO, 2015).

As pesquisas sociolinguísticas vêm mostrando que os diferentes falares podem suscitar nos indivíduos crenças e atitudes linguísticas diversas. É tarefa da Sociolinguística observar as atitudes linguísticas, já que fazem referência ao problema da avaliação, relativo às análises do falante quanto à sua variedade linguística e à de outros falantes. De certa forma, as atitudes linguísticas influenciam a variação e as mudanças que ocorrem em uma determinada língua.

As crenças e atitudes são estreitamente imbricadas, de modo que falar de uma precisa se referir à outra. Isso se deve, sobretudo porque uma complementa a outra e vice-versa. Segundo Barcelos (2007), o conceito de crença é tão antigo quanto nossa existência, pois, desde que o homem começou a pensar, ele passou acreditar em algo. Para autora, crença é

uma forma de pensamento, construções da realidade, maneira de ver e perceber o mundo e seus fenômenos, co-construídas em nossas experiências resultantes de um processo interativo de interpretação e (re)significação. Como tal, crenças são sociais (mas também individuais), dinâmicas, contextuais e paradoxais (BARCELOS, 2007, p. 113).

Para a autora, embora as crenças sejam dinâmicas, pela concepção de um olhar sociocultural, elas transformam-se no tempo ou até mesmo dentro de uma mesma situação; da mesma forma as atitudes segundo Lambert e Lambert (1981, p.101), nos estágios iniciais de seu desenvolvimento podem ser modificadas por novas experiências, até se solidificarem em determinados grupos e gerarem reações estereotipadas pela forte motivação a modos de padronizações sociais.

Assim, para Lambert e Lambert (1981, p. 100), uma atitude "é uma maneira organizada e coerente de pensar, sentir e reagir em relação a pessoas, grupos, problemas sociais ou, de modo mais geral, a qualquer acontecimento no ambiente circundante". Nesse sentido, a atitude linguística manifestada por um falante é marcada por preferências de aceitação ou negação diante de uma determinada variante linguística, dialeto, ou língua, sua/seu ou de outro; e pelo ajustamento social que propicia a classificação de variedades linguísticas particulares de acordo com padrões emocionais e de crenças.

Destaca-se que essas características são usadas com base nos componentes estruturantes da atitude linguística proposto por Lambert e Lambert (1981, p. 100), os "pensamentos e crenças, sentimentos e emoções, bem como tendência para reagir". A respeito desses componentes, Aguilera (2008) comenta que:

a atitude se constitui de três componentes colocados no mesmo nível: o saber ou crença (componente cognoscitivo); a valoração (componente afetivo); e a conduta (componente conativo), o que significa dizer que a atitude linguística de um indivíduo é o resultado da soma de suas crenças, conhecimentos, afetos e tendências a comportar-se de uma forma determinada diante de uma língua ou de uma situação sociolinguística. (AGUILERA, 2008, p. 106).

Apesar de serem identificados como mecanismos fundamentais para o conhecimento das atitudes, os componentes "não estão tão rigidamente sistematizados que não possam ser modificados por novas experiências" (LAMBERT; LAMBERT, 1972, p. 78). Por estas "novas experiências", entendem-se as relações sociais e/ou linguísticas dos falantes, experiências capazes de alterar os comportamentos, os saberes e a valoração.

E quando o julgamento é de forma positiva, de sua própria forma de falar, por exemplo, o falante manifesta identidade linguística sobre a variedade que usa e da comunidade de fala a que pertence, porém quando esse julgamento é de forma negativa, gera o que chamamos de preconceito 
linguístico.

O falante emite um julgamento sobre as variedades linguísticas, e associa a elas diferentes valores, hierarquizando-as: um modo de falar é visto como "desagradável" ou "feio", um outro como "cantado" e "lento", e outro, enfim, como "importante" e "conhecido", símbolo de signo de cultura. Linguisticamente falando, algumas pessoas têm uma atitude mais normativa, mais purista, e outras, uma atitude mais tolerante. (CARDOSO, 2015, p. 9-10).

Essa afirmativa mostra que a língua é capaz de integrar o homem socialmente ou deixá-lo às margens da sociedade; de lhe atribuir prestígio ou estigma; ascendê-lo socialmente ou colocá-lo no lugar mais baixo da pirâmide linguística dependendo do valor que lhe é atribuído quando usa a sua língua.

Dessa forma, o sentimento de estigma de falantes de grupos menores e menos prestigiados pode levá-lo ao não uso de sua forma de falar em detrimento da valoração das formas de prestígio de grupos maiores, assim como o sentimento de valorização e defesa da sua forma de falar e da sua comunidade podem contribuir para que seu dialeto permaneça vivo mesmo sob pressão das formas de prestígio

Corroborando com as ideias propostas aqui, Tarallo (1997, p.14), ao tratar do assunto, acrescenta, o conceito de identidade linguística, entendendo que as atitudes são "[...] armas usadas pelos residentes para demarcar seu espaço, sua identidade cultural, seu perfil de comunidade, de grupo social separado." De acordo com essa definição, a partir do momento em que o indivíduo se posiciona positivamente ou negativamente diante de uma variedade, ele se reveste de uma identidade que o diferencia de um grupo, etnia ou povo.

Estando a atitude sujeita às mudanças culturais e linguísticas de um grupo, cuja posição social apresente prestígio, sua função é medida por meio do uso de um instrumento que se adeque às variações e registre os graus de reações positivas ou negativos para serem medidos e organizados. Considerando os fatores sujeitos às mudanças, Lambert e Lambert (1981) destacam a dificuldade de se medir de forma direta processos psicológicos tão complexos quanto às atitudes.

Segundo os autores (1972, p. 83), a funcionalidade essencial das atitudes "afetam nossos julgamentos e percepções sobre outros, ajudam a determinar os grupos com que nos associamos às profissões que finalmente escolheremos e até as filosofias à sombra das quais vivemos". As mudanças de comportamentos dos componentes ou das atitudes são possíveis de ocorrer no decorrer das experiências modificadoras de preferências e do desenvolvimento e/ou ajustamento de hábitos.

\section{Procedimentos metodológicos}

Crenças e atitudes linguísticas na variação da vogal média posterior $/ \mathrm{o} />[\mathrm{u}]$ em posição tônica no português falado em Cametá-PA desenvolveu-se a partir dos pressupostos teórico-metodológicos da Sociolinguística laboviana; nos estudos sobre crenças e atitudes linguísticas baseado em Lambert e Lambert (1996); e nos parâmetros de coleta de dados e análise a pesquisa de Corbari (2013).

O corpus de análise foi coletado por meio de um questionário cedido aos participantes-colaboradores $^{5}$ da pesquisa. Para a elaboração e aplicação desse questionário duas etapas foram segui-

\footnotetext{
${ }^{5}$ Como exigências previstas, os colaboradores que residem em Cametá deveriam ser todos paraenses natos de Cametá, ou no caso de não terem nascidos na cidade, tenham vindo para a localidade nos primeiros anos de vida, e de modo geral, não terem fixado fora da localidade por mais de 2 (dois) anos. Os colaboradores que não residem em Cametá deveriam ser de outras regiões distante da localidade (ex: Belém, Mojú, Abaetetuba), pois os colaboradores de regiões vizinhas (como: Mocajuba, Limoeiro) poderiam influenciar na coleta dos dados por terem variantes linguísticas semelhantes. Salienta-se que o perfil dos colaboradores/participantes obedece ao critério de amostragem aleatória, a fim de possibilitar uma maior represen-
} 
das: na primeira etapa, um sujeito falante ${ }^{6}$ de Cametá gravou por duas vezes a leitura de um mesmo texto que apresentava exemplos de vocábulos com a vogal média posterior tônica /o/. Na primeira gravação, a vogal média posterior tônica /o/ dos vocábulos era lida alteada para [u], isto é, apresentava fortes traços fonético-fonológicos de alteamento.

Na segunda gravação, a vogal média posterior tônica /o/ dos vocábulos era mantida.

A escolha do informante voluntário para a produção da etapa da audição de vozes foi proposital, pois se desejava obter uma fala bastante contrastante em termos de traços fonético-fonológicos, e assim constituir um modelo de coleta de dados baseado no modelo de Lambert e Lambert (1968).

$\mathrm{Na}$ Segunda etapa, os áudios obtidos na fase anterior foram apresentados a um grupo de "juízes" (ouvintes que fizeram julgamentos), de forma isolada, por meio da técnica de "audição de vozes", e adaptação de Lambert e Lambert (1968), na qual o informante colaborador da pesquisa ouvia as gravações e, em seguida, preenchia um questionário que continha perguntas específicas sobre a variedade linguística, que estavam ouvindo, incluindo traços como beleza, caráter, amabilidade, dentre outros traços apresentados pelo dono da voz.

Para isso, os sujeitos participantes deveriam marcar (x) de acordo com sua opinião, se concordavam ou não com os tais traços da fala que ouviam. As opções sugeridas foram: concordo totalmente; concordo; concordo parcialmente; discordo totalmente; discordo e; discordo parcialmente, como podemos observar na (figura 01).

Esse questionário visou observar o impacto determinante dos comportamentos sociais e cognitivos na língua aqui investigada e obter as avaliações positivas ou negativas acerca do fenômeno de alteamento na tônica observado aqui.

Figura 01 - Perguntas específicas da audição de vozes para avaliar crenças e atitudes linguísticas dos falantes.

\section{A fala (modo de falar) que você acabou de ouvir é:}

\begin{tabular}{|l|l|l|l|l|l|l|l|}
\hline & $\begin{array}{l}\text { Concordo } \\
\text { Totalmente }\end{array}$ & Concordo & $\begin{array}{l}\text { Concordo } \\
\text { Parcialmente }\end{array}$ & $\begin{array}{l}\text { Discordo } \\
\text { Parcialmente }\end{array}$ & Discordo & $\begin{array}{l}\text { Discordo } \\
\text { Totalmente }\end{array}$ & \\
\hline Bonita & & & & & & & Feia \\
\hline Cantada & & & & & & & Não cantada \\
\hline Clara & & & & & & & Confusa \\
\hline Chiada & & & & & & & Não chiada \\
\hline Rápida & & & & & & & Lenta \\
\hline Simples & & & & & & & Complicada \\
\hline Agradável & & & & & & & Desagradável \\
\hline Melodiosa & & & & & & & Sem Melodia \\
\hline Conhecida & & & & & & & Desconhecida \\
\hline Importante & & & & & & & Sem importância \\
\hline
\end{tabular}

Fonte: Adaptação a partir de SILVA (2015) ${ }^{7}$.

tatividade social, pois, supõe-se que dessa forma dá-se a oportunidade, para os mais variados sujeitos pertinentes a grupos sociais diferentes, de expressarem suas opiniões a respeito do tema em apreço (cf. TARALLO, 1994, p. 27).

6 Destaca-se que a leitura desse texto foi feito por um falante voluntário (cametaense) que não fez parte da amostra estratificada da pesquisa, apenas cedeu o material linguístico para que os sujeitos-colaboradores (no papel de juízes) pudessem expressar suas avaliações positivas ou negativas, acerca do fenômeno de alteamento na tônica observado aqui. Este sujeito participante da pesquisa apenas cedeu o material linguístico à pesquisa, mas não teve seus dados considerados para análise.

7 Questionário retirado do Trabalho de Conclusão de Curso de SILVA (2019) “Atitudes linguísticas diante dos ideofones da variedade do português falado em Cametá-PA". 
A análise dos dados das respostas desse questionário partirá a somatória do percentual dos itens concordo totalmente, concordo e concordo parcialmente encapsulados no grupo de "atitudes positivas"; e o discordo parcialmente, discordo e discordo totalmente para "atitudes negativas". E análise incidirá apenas sobre as audições da leitura com vocábulos que apresentam a posterior alteada.

O quadro de amostragem social da pesquisa obedeceu ao critério de amostragem aleatória, e os 24 (vinte e quatro) colaboradores foram estratificados em: a) procedência (12 cametaenses e 12 não cametaenses); b) faixa etária (12 de 15 a 29 anos e 30 a 45 anos); c) sexo/gênero (12 feminino e 12 masculino) e; d) nível de escolaridade (08 com pouca escolaridade, 08 com nível médio e 08 com nível superior). Todos os colaboradores da pesquisa são paraenses natos de Cametá ${ }^{8}$ ou de outra localidade do estado do Pará.

Quadro 01 - Plano de Amostra Estratificada dos Informantes

\begin{tabular}{|c|c|c|c|}
\hline FAIXA ETÁRIA & SEXO & ESCOLARIDADE & PROCEDÊNCIA \\
\hline \multirow{12}{*}{$\begin{array}{c}\mathrm{I} \\
(15 \text { a } 29 \text { anos }) \\
(12 \text { informantes })\end{array}$} & \multirow{6}{*}{$\begin{array}{l}\text { FEMININO } \\
(06)\end{array}$} & \multirow{2}{*}{ Pouca Escolaridade } & Reside em Cametá \\
\hline & & & Não Reside em Cametá \\
\hline & & \multirow{2}{*}{ Ensino Médio } & Reside em Cametá \\
\hline & & & Não Reside em Cametá \\
\hline & & \multirow{2}{*}{ Ensino Superior } & Reside em Cametá \\
\hline & & & Não Reside em Cametá \\
\hline & \multirow{6}{*}{$\begin{array}{c}\text { MASCULINO } \\
(06)\end{array}$} & \multirow{2}{*}{ Pouca Escolaridade } & Reside em Cametá \\
\hline & & & Não Reside em Cametá \\
\hline & & \multirow{2}{*}{ Ensino Médio } & Reside em Cametá \\
\hline & & & Não Reside em Cametá \\
\hline & & \multirow{2}{*}{ Ensino Superior } & Reside em Cametá \\
\hline & & & Não Reside em Cametá \\
\hline \multirow{12}{*}{$\begin{array}{c}\text { II } \\
(30 \text { a } 45 \text { anos }) \\
\text { (12 informantes) }\end{array}$} & \multirow{6}{*}{$\begin{array}{l}\text { FEMININO } \\
(06)\end{array}$} & \multirow{2}{*}{ Pouca Escolaridade } & Reside em Cametá \\
\hline & & & Não Reside em Cametá \\
\hline & & \multirow{2}{*}{ Ensino Médio } & Reside em Cametá \\
\hline & & & Não Reside em Cametá \\
\hline & & \multirow{2}{*}{ Ensino Superior } & Reside em Cametá \\
\hline & & & Não Reside em Cametá \\
\hline & \multirow{6}{*}{$\begin{array}{c}\text { MASCULINO } \\
(06)\end{array}$} & \multirow{2}{*}{ Pouca Escolaridade } & Reside em Cametá \\
\hline & & & Não Reside em Cametá \\
\hline & & \multirow{2}{*}{ Ensino Médio } & Reside em Cametá \\
\hline & & & Não Reside em Cametá \\
\hline & & \multirow{2}{*}{ Ensino Superior } & Reside em Cametá \\
\hline & & & Não Reside em Cametá \\
\hline
\end{tabular}

Fonte: Elaboração própria

E como o objeto de estudo da atitude linguística não é a língua, e sim quem as usa, o foco desta investigação são os falantes, na maneira como se comportam diante da língua e dos fatos linguísticos.

Destaca-se que a avaliação dos fatores sociodemográficos "escolaridade, idade, sexo" será considerada para este estudo somente dos juízes cametaenses. Então, em 12 informantes que responderam cada um no primeiro questionário 10 questões sobre atitudes linguísticas a partir de estímulos provocados pelos áudios com a vogal alvo /o/ ora alteada [u], ora mantida [o]. O resultado final foi 120 respostas sobre as crenças e atitudes aqui investigadas advindas da quantidade de perguntas, 10 questões, multiplicadas pelo número de colaboradores, 12 . No fator procedência dos informantes incluirá-se as avaliações dos falantes cametaenses.

8 No caso de não terem nascidos na cidade, era necessário que tivessem vindo para a localidade nos primeiros anos de vida, e de modo geral, não terem fixado residência fora da localidade por mais de 2 (dois) anos. 


\section{Análise e discussão dos resultados}

A análise da atitude linguística, apresentada aqui, será abordada a partir dos julgamentos dos falantes cametaenses frente ao alteamento da vogal média posterior /o/ em posição tônica. Para tanto, a constituição do objeto de análise se deu com base no juízo de valor apresentado pelos informantes e as opiniões cedidas pela amostra possibilitam a inferência das crenças e atitudes linguísticas a respeito do modo como o sujeito cametaense julga seu próprio modo de falar.

Para a análise foi levado em conta também os níveis cognitivo, afetivo e conativo presentes no comportamento linguístico do falante (LAMBERT; LAMBERT, 1968). É nesse pressuposto que esta análise inscreve-se, nos juízos de valor atribuídos ao dialeto cametaense e aos falantes desse dialeto, por meio de crenças e valores tanto de falantes cametaense como de não cametaenses.

As opiniões cedidas pelos informantes possibilitaram a compreensão da identidade linguística a respeito do modo de falar cametaense. Para tanto, a análise dos dados foi realizada de acordo com as variáveis sociodemográficas - faixa etária, sexo, escolaridade (cametaenses) e procedência (cametaenses e não cametaenses).

Assim, as discussões dos resultados desenvolvidas aqui, serão apresentadas a partir das análises isoladas de três variáveis (sexo, escolaridade e faixa etária). Para cada variável, os três componentes da atitude cognitiva, afetiva e conativa serão discutidos.

Em relação à variável sexo/gênero, observamos em função dos componentes das atitudes: conativo, cognitivo e afetivo que há diferença quanto à avaliação dos falantes, estabelecida principalmente pelo aspecto cognitivo, conforme expressos na tabela 01.

Tabela 01 - A influência do fator "sexo" sobre as atitudes linguísticas dos falantes cametaenses acerca do alteamento vocálico na tônica da média posterior /o/.

\begin{tabular}{|c|c|c|c|c|}
\hline \multirow{2}{*}{\multicolumn{3}{|c|}{ Componentes da atitude }} & \multicolumn{2}{|c|}{ Percentual } \\
\hline & & & Feminino & Masculino \\
\hline \multirow{3}{*}{ COGNITIVO } & \multirow{10}{*}{ 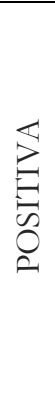 } & Conhecida & \multirow{3}{*}{$78 \%$} & \multirow{3}{*}{$67 \%$} \\
\hline & & Importante & & \\
\hline & & Clara & & \\
\hline \multirow{4}{*}{ CONATIVO } & & Cantada & \multirow{4}{*}{$63 \%$} & \multirow{4}{*}{$50 \%$} \\
\hline & & Chiada & & \\
\hline & & Lenta & & \\
\hline & & Simples & & \\
\hline \multirow{3}{*}{ AFETIVO } & & Bonita & \multirow{3}{*}{$39 \%$} & \multirow{3}{*}{$50 \%$} \\
\hline & & Agradável & & \\
\hline & & Melodiosa & & \\
\hline \multirow{3}{*}{ COGNITIVO } & \multirow{10}{*}{ 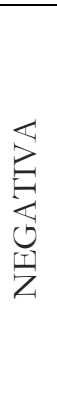 } & Desconhecida & \multirow{3}{*}{$22 \%$} & \multirow{3}{*}{$33 \%$} \\
\hline & & Sem importância & & \\
\hline & & Confusa & & \\
\hline \multirow{4}{*}{ CONATIVO } & & Não cantada & \multirow{4}{*}{$37 \%$} & \multirow{4}{*}{$50 \%$} \\
\hline & & Não chiada & & \\
\hline & & Rápida & & \\
\hline & & Complicada & & \\
\hline \multirow{3}{*}{ AFETIVO } & & Feia & \multirow{3}{*}{$61 \%$} & \multirow{3}{*}{$50 \%$} \\
\hline & & Desagradável & & \\
\hline & & Sem Melodia & & \\
\hline
\end{tabular}

Fonte: Elaboração própria

Cardoso (2015) aponta que a avaliação linguística feita por um falante depende, em grande parte, das atitudes linguísticas pré-estabelecidas socialmente em relação ao dialeto, à classe social e ao grupo étnico desse falante. Logo, uma das justificativas que poderíamos apontar para o fato de as mulheres receberem melhor as formas linguísticas não formais e/ou vernaculares da variedade linguística cametaense, é ocasionada pela percepção sociolinguística dessa classe de falantes com 
maior sensibilidade e reconhecimento do fato que não existe língua superior ou inferior em termos de comunicabilidade. Entretanto, em relação à afetividade, as mulheres não parecem estabelecer laços emotivos com tal forma linguística.

Os pares presentes no componente cognitivo manifestam as crenças e saberes dos informantes sobre o modo de falar cametaense partindo de sua consciência sociolinguística, e conforme os dados, as mulheres, além de reconhecerem como legítima o alteamento da vogal posterior em posição tônica, reagem positivamente.

Assim, de acordo com as crenças, opiniões de importância e conhecimento, a tabela acima aponta para a soma dos dados das reações em que os participantes cametaenses manifestaram acerca do linguajar cametaense atitudes positivas, com percentual de $78 \%$, em escala decrescente, o masculino indica $67 \%$.

E em relação à demonstração pelas mulheres do fator afetivo com atitude negativa pode implicar que esse componente, se comparado com o cognitivo e conativo é o que mais nos suscita inferências subjetividade pelo alcance das reações emotivas dos falantes, em relação ao próprio modo de falar. Pode-se concluir também que a valoração ou não da linguagem cametaense está sujeita ao ajustamento social do falante, e diretamente relacionado ao status que o linguajar/ ou falar cametaense recebe.

Portanto, as mulheres podem apresentar menor sensibilidade a formas tidas como não cultas / vernaculares, como tendência ao enquadramento e aceitabilidade social na comunidade. Em linhas gerais, na variável sexo/gênero observa-se um maior percentual de reações positivas dos falantes cametaenses do sexo feminino, pois este sexo possui maior nível de aceitabilidade sobre a fala cametaense.

Para a variável escolaridade, os falantes de Cametá foram agrupados em três grupos: pouca escolaridade (PE), nível médio (NM) e nível superior (NS). Os juízes cametaenses com nível superior apresentaram um predomínio de atitudes positivas nos três componentes em relação ao alteamento vocálico na tônica da média posterior /o/ > [u], como mostra a tabela 02.

Tabela 02 - A influência do fator "escolaridade" sobre as atitudes linguísticas positivas dos falantes cametaenses acerca do alteamento vocálico na tônica da média posterior /o/.

\begin{tabular}{|c|c|c|c|c|c|}
\hline \multirow{2}{*}{\multicolumn{3}{|c|}{ Componentes da atitude }} & \multicolumn{3}{|c|}{ Nível de escolaridade } \\
\hline & & & Pouca escolaridade & Nível médio & Nível superior \\
\hline \multirow{3}{*}{ COGNITIVO } & \multirow{10}{*}{ 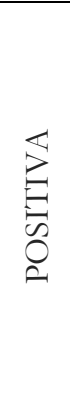 } & Conhecida & \multirow{3}{*}{$67 \%$} & \multirow{3}{*}{$67 \%$} & \multirow{3}{*}{$83 \%$} \\
\hline & & Importante & & & \\
\hline & & Clara & & & \\
\hline \multirow{4}{*}{ CONATIVO } & & Cantada & \multirow{4}{*}{$56 \%$} & \multirow{4}{*}{$31 \%$} & \multirow{4}{*}{$63 \%$} \\
\hline & & Chiada & & & \\
\hline & & Lenta & & & \\
\hline & & Simples & & & \\
\hline \multirow{3}{*}{ AFETIVO } & & Bonita & \multirow{3}{*}{$17 \%$} & \multirow{3}{*}{$25 \%$} & \multirow{3}{*}{$75 \%$} \\
\hline & & Agradável & & & \\
\hline & & Melodiosa & & & \\
\hline \multirow{3}{*}{ COGNITIVO } & \multirow{10}{*}{ 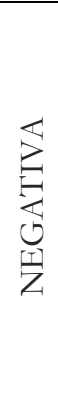 } & Desconhecida & \multirow{3}{*}{$33 \%$} & \multirow{3}{*}{$33 \%$} & \multirow{3}{*}{$17 \%$} \\
\hline & & Sem importância & & & \\
\hline & & Confusa & & & \\
\hline \multirow{4}{*}{ CONATIVO } & & Não cantada & \multirow{4}{*}{$44 \%$} & \multirow{4}{*}{$69 \%$} & \multirow{4}{*}{$37 \%$} \\
\hline & & Não chiada & & & \\
\hline & & Rápida & & & \\
\hline & & Complicada & & & \\
\hline \multirow{3}{*}{ AFETIVO } & & Feia & \multirow{3}{*}{$83 \%$} & \multirow{3}{*}{$75 \%$} & \multirow{3}{*}{$25 \%$} \\
\hline & & Desagradável & & & \\
\hline & & Sem Melodia & & & \\
\hline
\end{tabular}

Fonte: Elaboração própria

De acordo com os dados da tabela acima, os pares do componente cognitivo mostrou que 
os participantes/colaboradores cametaenses do nível superior manifestaram $83 \%$ de atitudes positivas em relação às características de conhecimento e valoração sobre as expressões linguísticas empregadas em sua comunidade, enquanto que os de pouca escolaridade e ensino médio apontaram $63 \%$ de reações positivas.

No componente conativo, os participantes agrupados na categoria ensino médio demonstraram $69 \%$ de atitudes negativas em relação ao português falado na variedade de Cametá. E no componente afetivo, os falantes cametaenses de pouca escolaridade apresentaram um índice de 83\% de atitudes negativas.

De modo geral, pode-se dizer que quanto maior for o grau de escolaridade, maior será a consciência sociolinguística que os falantes nativos apresentarão sobre seu próprio falar, e quanto menor for o grau de instrução, menor é a tendência de reação de valoração quanto às marcas linguísticas regionais, principalmente no fator afetivo, que revela pouca identidade as formas linguísticas com variante não padrão, com $17 \%$ para os falantes de pouca escolaridade e $25 \%$ para os falantes de ensino médio. Logo, quanto mais alto for o nível de escolaridade, menor será o estigma.

Em relação à variável faixa etária do informante, a partir da análise de um corpus formado por duas faixas etárias, observamos que os falantes de 30 a 45 anos apresentam mais atitudes positivas nos três componentes (cognitivo, conativo e afetivo), do que os falantes de 15 a 29 anos sobre o fenômeno do alteamento vocálico na tônica de $/ \mathrm{o} />[\mathrm{u}]$, conforme verificado na tabela 03 .

Tabela 03 - A influência do fator "faixa etária" sobre as atitudes linguísticas dos falantes cametaenses acerca do alteamento vocálico na tônica da média posterior /o/.

\begin{tabular}{|c|c|c|c|c|}
\hline \multirow{2}{*}{\multicolumn{3}{|c|}{ Componentes da atitude }} & \multicolumn{2}{|c|}{ Percentual } \\
\hline & & & 15-29 anos & $30-45$ anos \\
\hline \multirow{3}{*}{ COGNITIVO } & \multirow{10}{*}{ 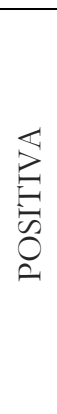 } & Conhecida & \multirow{3}{*}{$72 \%$} & \multirow{3}{*}{$72 \%$} \\
\hline & & Importante & & \\
\hline & & Clara & & \\
\hline \multirow{4}{*}{ CONATIVO } & & Cantada & \multirow{4}{*}{$42 \%$} & \multirow{4}{*}{$71 \%$} \\
\hline & & Chiada & & \\
\hline & & Lenta & & \\
\hline & & Simples & & \\
\hline \multirow{3}{*}{ AFETIVO } & & Bonita & \multirow{3}{*}{$22 \%$} & \multirow{3}{*}{$67 \%$} \\
\hline & & Agradável & & \\
\hline & & Melodiosa & & \\
\hline \multirow{3}{*}{ COGNITIVO } & \multirow{10}{*}{ 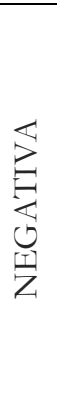 } & Desconhecida & \multirow{3}{*}{$28 \%$} & \multirow{3}{*}{$28 \%$} \\
\hline & & Sem importância & & \\
\hline & & Confusa & & \\
\hline \multirow{4}{*}{ CONATIVO } & & Não cantada & \multirow{4}{*}{$58 \%$} & \multirow{4}{*}{$29 \%$} \\
\hline & & Não chiada & & \\
\hline & & Rápida & & \\
\hline & & Complicada & & \\
\hline \multirow{3}{*}{ AFETIVO } & & Feia & \multirow{3}{*}{$78 \%$} & \multirow{3}{*}{$33 \%$} \\
\hline & & Desagradável & & \\
\hline & & Sem Melodia & & \\
\hline
\end{tabular}

Fonte: Elaboração própria

A opção pelo uso do fator faixa etária neste estudo, de acordo com Tarallo (1994, p. 65) "um recorte transversal da amostra sincrônica em função da faixa etária dos informantes", surge do intuito de verificarmos como a idade do falante interferiu nas suas atitudes. E pelos dados da tabela 03, os participantes/colaboradores jovens apresentaram deslealdade em relação a um traço caracterizador da sua linguagem, enquanto que os adultos tenham apresentado maior índice de aprovação às formas alteadas da vogal posterior /o/ em posição tônica, o que de certa forma já era o esperado, pois os adultos tendem a ser mais tolerantes a variedades linguísticas menos formais, pois se acredita que as pessoas da segunda faixa etária por possuírem maior tempo na escola, e consequentemente, de acesso à língua padrão, esses falantes têm maior maturidade linguística, e discer- 
nimento entre as diferentes formas de uso da língua.

Para a variável geográfica procedência dos falantes (juízes colaboradores), caracterizada a partir de dois fatores, cametaense e não cametaense, tínhamos como objetivo registar se a origem do falante-juiz influenciava na atribuição de prestígio ou desprestígio linguístico acerca do alteamento na tônica de $/ \mathrm{o} />/ \mathrm{u} /$.

Concluímos por meio do teste de atitude indireto que os falantes cametaenses e não cametaenses, conforme tabela 04 , apresentam o mesmo percentual de atitudes positivas, $72 \%$, para o componente cognitivo; $56 \%$ cametaense e $54 \%$ em relação ao afetivo; apresentando diferenças somente no componente afetivo, pois os cametaenses demonstraram $61 \%$ de atitudes negativas para este traço, não revelando identidade e afetividade com a variedade investigada. Logo, as variações no uso da língua são condicionadas também pelo comportamento assumido pelos falantes, rejeitando alguns modos de falar e manifestando preferências por outros (CORBARI, 2013).

Tabela 04 - A influência do fator "procedência" sobre as atitudes linguísticas dos falantes cametaenses e não cametaenses acerca do alteamento vocálico na tônica da média posterior /o/.

\begin{tabular}{|c|c|c|c|c|}
\hline \multirow{2}{*}{\multicolumn{3}{|c|}{ Características da fala }} & \multicolumn{2}{|c|}{ Percentual } \\
\hline & & & Cametaenses & Não Cametaenses \\
\hline \multirow{3}{*}{ COGNITIVO } & \multirow{10}{*}{$\begin{array}{l}\varangle \\
己 \\
\Xi \\
0 \\
0 \\
0\end{array}$} & Conhecida & \multirow{3}{*}{$72 \%$} & \multirow{3}{*}{$72 \%$} \\
\hline & & Importante & & \\
\hline & & Clara & & \\
\hline \multirow{4}{*}{ CONATIVO } & & Cantada & \multirow{4}{*}{$56 \%$} & \multirow{4}{*}{$54 \%$} \\
\hline & & Chiada & & \\
\hline & & Lenta & & \\
\hline & & Simples & & \\
\hline \multirow{3}{*}{ AFETIVO } & & Bonita & \multirow{3}{*}{$39 \%$} & \multirow{3}{*}{$75 \%$} \\
\hline & & Agradável & & \\
\hline & & Melodiosa & & \\
\hline \multirow{3}{*}{ COGNITIVO } & \multirow{10}{*}{ 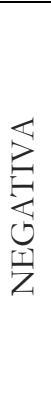 } & Desconhecida & \multirow{3}{*}{$28 \%$} & \multirow{3}{*}{$28 \%$} \\
\hline & & Sem importância & & \\
\hline & & Confusa & & \\
\hline \multirow{4}{*}{ CONATIVO } & & Não cantada & \multirow{4}{*}{$44 \%$} & \multirow{4}{*}{$46 \%$} \\
\hline & & Não chiada & & \\
\hline & & Rápida & & \\
\hline & & Complicada & & \\
\hline \multirow{3}{*}{ AFETIVO } & & Feia & \multirow{3}{*}{$61 \%$} & \multirow{3}{*}{$25 \%$} \\
\hline & & Desagradável & & \\
\hline & & Sem Melodia & & \\
\hline
\end{tabular}

Fonte: Elaboração própria

Dado relevante desse estudo vem dos falantes que não residem em Cametá, pois nos levam a inferir pelos resultados obtidos expostos pelos percentuais que eles julgam de forma consciente o modo de falar cametaense, expressando sentimentos de valoração em relação às formas de falar da comunidade cametaense e não manifestam atitude de preconceito em relação ao alteamento de $/ \mathrm{O} />[\mathrm{u}]$, pois para os três componentes que definem a atitude há percentual elevado de aceitabilidade para a variação em análise.

Então, afirmamos a partir disso que:

(a) O alteamento de /o/ presente em Cametá é percebido pelos falantes/ouvintes;

(b) Os falantes reconhecem o alteamento de /o/;

(c) associam as diferenças linguísticas as diferenças geográficas;

(d) valoração concebida pelas diferenças observadas à procedência do falante.

\section{Considerações finais}

No que diz respeito à influência dos fatores sociais (extralinguísticos) no processo de avalia- 
ção do fenômeno de alteamento da média /o/ > [u] em posição tônica, os resultados apontam que na variável faixa etária obteve-se um maior percentual de atitudes negativas dos falantes cametaenses da $1^{a}$ faixa etária do que a $2^{a}$ faixa etária, em relação às formas linguísticas da comunidade.

Observou-se, contudo, um predomínio de atitudes positivas dos falantes com nível superior, porém, notou-se um grande percentual de atitudes negativas nas demais variáveis, o que nos leva a concluir que os falantes de Cametá apresentam um estigma linguístico bastante elevado sobre o fenômeno de alteamento da vogal /o/ em posição tônica, ou seja, os próprios cametaenses julgam de forma negativa seu linguajar, consequentemente negando sua identidade linguística e sua crença.

Fernández (1998) argumenta que uma atitude negativa pode levar ao abandono e ao esquecimento de uma língua, impedindo assim a difusão de uma variante ou uma mudança linguística. Com base nisso, esta pesquisa demostrou que o falante tem uma influência significativa sobre o avanço ou recuo de um dado fenômeno variacionista de sua comunidade de fala, a partir de suas crenças e atitudes linguísticas. O falante, por exemplo, julgando de maneira pejorativa, e acreditando que sua língua é "incorreta", "feia”, emitirá, consequentemente, valorações negativas diante dela, e deixa, então, de usá-la.

A escolha de uma determinada língua ou variedade linguística é produto da manifestação de preferência e de convenções sociais do status e prestígio que se tem sobre essa língua (FERNÁNDEZ, 1998, p. 179). Assim, o sujeito prefere usar a forma de maior prestígio social, mesmo nutrindo laços afetivos para com sua terra natal, contribuindo para o desaparecimento linguístico de sua comunidade. As atitudes linguísticas dos falantes diante do linguajar cametaense é um fator determinante para a mudança linguística, desconstruindo uma identidade linguística

Concluiu-se, a partir disso, que as atitudes linguísticas dos falantes diante do alteamento /o/ $>[\mathrm{u}]$ na tônica pode constituir um fator de enfraquecimento desse fenômeno na linguagem cametaense, visto que, os resultados obtidos por meio da amostra indicaram que os informantes nativos de Cametá, predominantemente reagiram negativamente diante da variedade local.

Esta pesquisa nos mostrou que a depender das atitudes linguísticas que os falantes tomam frente a um determinado fenômeno linguístico presente na sua comunidade, este pode permanecer ou desaparecer da comunidade. Se o falante julga de maneira pejorativa, alimentando crenças de que sua língua é "incorreta", é "feia" emitindo valorações negativas diante dela, deixa de usá-la ou opta por não usá-la tendo preferência por outra de mais prestígio social, mesmo nutrindo laços afetivos para com sua terra natal fazendo com que neste caso, as formas linguísticas de sua comunidade desapareçam. Outro fator que contribui para o desaparecimento das formas linguísticas é o preconceito linguístico sofrido de pessoas de outros lugares, transformando essas formas linguísticas em formas fortemente estigmatizadas.

Esperamos ter contribuído de forma significativa para a comunidade científica, especificamente da área sociolinguística, assim como também para a comunidade em geral. Vale ressaltar que esta pesquisa pode ser ampliada com o intuito de se chegar a novas conclusões ou oferecer dados para futuras investigações acerca das atitudes linguísticas que adotam os falantes diante do fenômeno da variação linguística. É importante que se faça significar que não existe língua e/ou fala errada, que é preciso respeitar as mais variadas formas de expressão da língua e respeitar os falantes dessas variedades linguísticas. Contribuindo para a diminuição do preconceito linguístico e a constituição da identidade linguística do falante.

\section{Referências}

AGUILERA, V. de A. Crenças e atitudes linguísticas: o que dizem os falantes das capitais brasileiras. Estudos Lingüísticos, São Paulo, v.2, 2008.

BARCELOS, Ana Maria Ferreira. Reflexões acerca da mudança de crenças sobre ensino e aprendizagem de línguas. Revista Brasileira de Linguística Aplicada, belo Horizonte - UFMG, 
v. 7, n. 2, 2007, p.108-138.

CARDOSO, Denise Porto. Atitudes linguísticas e avaliações subjetivas de alguns dialetos brasileiros. São Paulo: Blucher, 2015.

COELHO, Izete Lehmkuhl et al. Sociolinguística. Florianópolis: LLV/CCE/UFSC, 2012.

CORBARI (2013), Clarice Cristina. Atitudes linguísticas: um estudo nas localidades (ISSN 2238-8060) paranaenses de Irati e Santo Antônio do Sudoeste. 2013. 259 f. Tese Letras - Programa de PósGraduação em Letras e Linguística, Universidade Federal da Bahia - UFBA, Bahia, 2013.

COSTA, Raquel M. S. A alternância das formas pronominais tu, você e o (a) senhor (a) na função de sujeito no Português falado em Cametá-PA. Tese (Doutorado em Linguística) Programa de Pós-Graduação em Linguística, Universidade Federal do Ceará, Fortaleza, 2016.

FAGGION, C. M. Estigma, cultura e atitude: investigações preliminares sobre o binômio prestígio/estigmatização na linguagem da Região de Colonização Italiana da Serra Gaúcha. In: FROSI, V. M.; FAGGION, C. M.; DAL CORNO, G. O. M. Estigma: cultura e atitudes linguísticas. Caxias do Sul: EDUCS, 2010. p.61-78.

FERNÁNDEZ, Francisco Moreno. Principios de sociolinguística y socioogía del linguaje. Barcelona. Editorial Ariel, S.A. 1998.

ILARI, Rodolfo; BASSO, Renato. O português da gente: a língua que estudamos, a língua que falamos. São Paulo: Contexto, 2006.

LAMBERT,W.W.; LAMBERT, W. E. Psicologia social. Rio de Janeiro: Zahar, 1968.

LAMBERT,W.W.; LAMBERT, W. E. Psicologia social. Tradução: Álvaro Cabral. 3 ed. Rio de Janeiro: Zahar, 1972.

RODRIGUES, Doriedson S. Da zona urbana a rural/entre a tônica e a pretônica: alteamento /o/ > [u] no português falado no município de Cametá/Ne paraense: uma abordagem variacionista. 2005. 387 f. Dissertacao (Mestrado em Letras) - Universidade Federal do Pará, Belém, 2005.

SILVA, G.M.M . Atidudes linguísticas diante dos ideofones na variedade do português falado em Cametá-Pa. Monografia (Graduação em Letras-Língua Portuguesa) - Faculdade de Linguagem, Universidade Federal do Pará - UFPA Cametá, 2019.

TARALLO, F. L. A pesquisa sociolinguística. 4.ed. São Paulo: Ática, 1994.

TARALLO, F. L. A pesquisa sociolinguística. 5.ed. São Paulo: Ática, 1997.

SILVA NETO, Serafim. 1988. História da Língua Portuguesa. 4 Ed. Rio de Janeiro: presença, Brasília, 1998. 